\title{
Location-specific quantification of protein-bound metal ions by X-ray anomalous dispersion: Q-XAD
}

\section{Julia J. Griese and Martin Högbom}

Acta Cryst. (2019). D75, 764-771

\section{$\square$ IUCr Journals CRYSTALLOGRAPHY JOURNALS ONLINE \\ Copyright (C) International Union of Crystallography \\ Author(s) of this article may load this reprint on their own web site or institutional repository provided that this cover page is retained. Republication of this article or its storage in electronic databases other than as specified above is not permitted without prior permission in writing from the IUCr. \\ For further information see http://journals.iucr.org/services/authorrights.html}


STRUCTURAL BIOLOGY

ISSN 2059-7983

Received 2 May 2019

Accepted 10 July 2019

Edited by M. Schiltz, Fonds National de la Recherche, Luxembourg

Keywords: metal quantification; quantitative $\mathrm{X}$-ray anomalous dispersion; R2-like ligandbinding oxidase; Q-XAD; X-ray crystallography.

Supporting information: this article has supporting information at journals.iucr.org/d

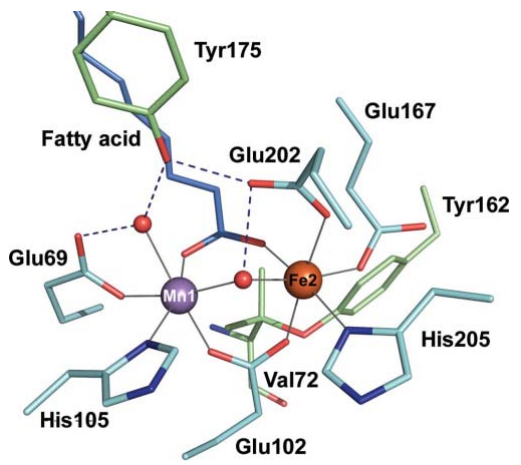

C 2019 International Union of Crystallography

\section{Location-specific quantification of protein-bound metal ions by X-ray anomalous dispersion: Q-XAD}

\author{
Julia J. Griese ${ }^{\mathrm{a}, \mathrm{b} *}$ and Martin Högbom ${ }^{\mathrm{a}}$
}

\begin{abstract}
${ }^{\mathbf{a}}$ Department of Biochemistry and Biophysics, Stockholm University, 10691 Stockholm, Sweden, and ${ }^{\mathbf{b}}$ Department of Cell and Molecular Biology, Uppsala University, Box 596, 75124 Uppsala, Sweden. *Correspondence e-mail: julia.griese@icm.uu.se
\end{abstract}

Here, a method is described which exploits X-ray anomalous dispersion (XAD) to quantify mixtures of metal ions in the binding sites of proteins and can be applied to metalloprotein crystals of average quality. This method has successfully been used to study site-specific metal binding in a protein from the R2-like ligand-binding oxidase family which assembles a heterodinuclear $\mathrm{Mn} / \mathrm{Fe}$ cofactor. While previously only the relative contents of $\mathrm{Fe}$ and $\mathrm{Mn}$ in each metal-binding site have been assessed, here it is shown that the method can be extended to quantify the relative occupancies of at least three different transition metals, enabling complex competition experiments. The number of different metal ions that can be quantified is only limited by the number of highquality anomalous data sets that can be obtained from one crystal, as one data set has to be collected for each transition-metal ion that is present (or is suspected to be present) in the protein, ideally at the absorption edge of each metal. A detailed description of the method, Q-XAD, is provided.

\section{Introduction}

About half of all enzymes are estimated to contain metallocofactors (Andreini et al., 2008). To understand how these cofactors exert their function, we must understand their structure. The crystallographic analysis of metalloproteins faces additional challenges in addition to those associated with macromolecular crystallography in general, such as the susceptibility of metal sites to X-ray photoreduction, which can drastically alter the structure of the cofactor and its environment (Bowman et al., 2016). However, the absorption of X-rays in the energy range of synchrotron beamlines by metal ions, particularly transition-metal ions, also provides unique possibilities. Commonly, the anomalous dispersion of $\mathrm{X}$-rays (XAD) by protein-bound metal ions is exploited for phase determination. Sometimes, it is used to unequivocally identify protein-bound metal ions. Here, we show that it can also be used to quantify mixtures of different metal ions in metal-binding sites. The method can be used to study metal specificity and the assembly mechanisms of mixed-metal cofactors in vitro. While a number of different methods are able to quantify protein-bound metal ions with high precision, such as inductively coupled plasma mass spectrometry (ICP-MS) or total reflection X-ray fluorescence (TXRF), only quantitative $\mathrm{XAD}(\mathrm{Q}-\mathrm{XAD})$ can provide location-specific information.

Q-XAD has proven instrumental to the study of our model system, the R2-like ligand-binding oxidase (R2lox), which harbors a heterodinuclear $\mathrm{Mn} / \mathrm{Fe}$ cofactor. The two metal ions are bound next to each other, with four glutamates and two histidines forming two nearly symmetrical binding sites 
[Fig. 1(a)]. Yet $\mathrm{Mn}$ is bound specifically in the N-terminal binding site (site 1 ) and $\mathrm{Fe}$ in the $\mathrm{C}$-terminal binding site (site 2), as determined by XAD (Andersson \& Högbom, 2009; Griese et al., 2013). We have previously used Q-XAD in Mn versus $\mathrm{Fe}$ competition experiments, which showed that site 2 of R2lox prefers $\mathrm{Fe}$ over $\mathrm{Mn}$, whereas site 1 contains equal amounts of both metals in the absence of oxygen, but almost exclusively Mn in the presence of oxygen (Griese et al., 2013). According to the Irving-Williams (IW) series, the stability of

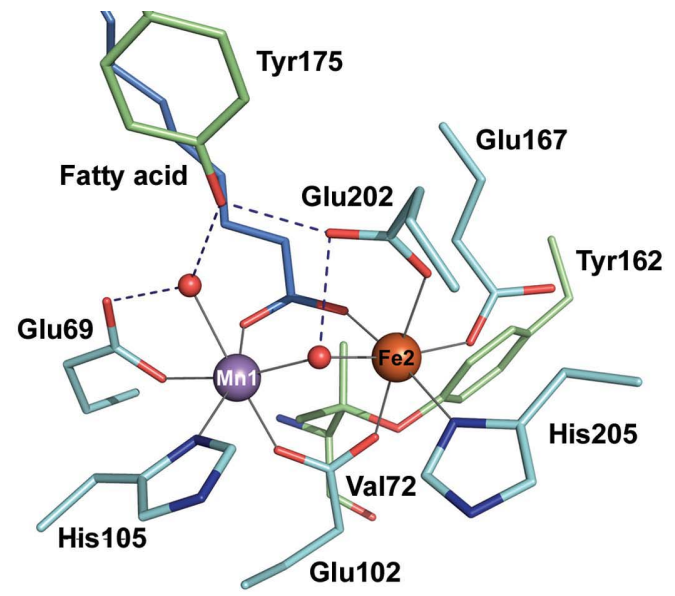

(a)

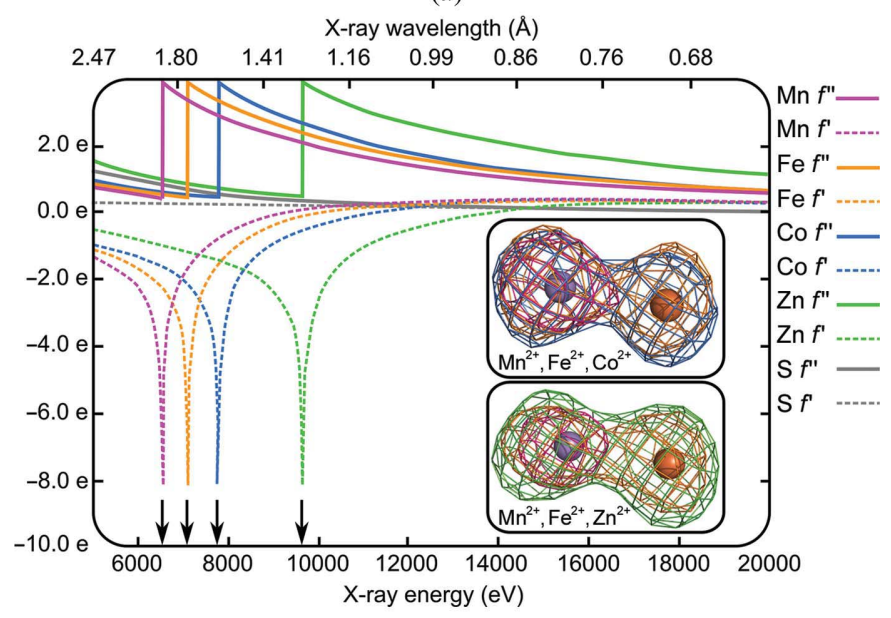

Figure 1

(b)

(a) Active-site structure of R2lox in the oxidized resting state (PDB entry 4hr0; Griese et al., 2013). Metal-ligand bonds are indicated by gray lines and hydrogen bonds by dashed blue lines. The $\mathrm{Mn} / \mathrm{Fe}$ cofactor catalyzes the formation of an ether cross-link between the $\mathrm{C}^{\beta}$ atom of Val72 and the phenolic $\mathrm{O}$ atom of Tyr162 (Griese et al., 2013, 2018). (b) The graph shows the dispersion, or real $\left(f^{\prime}\right)$, and absorption, or imaginary $\left(f^{\prime \prime}\right)$, components of the anomalous dispersion of X-rays by $\mathrm{Mn}, \mathrm{Fe}, \mathrm{Co}, \mathrm{Zn}$ and S (adapted from http://skuld.bmsc.washington.edu/scatter/AS_index.html). Only Mn displays an appreciable anomalous signal at the Mn edge, but at the $\mathrm{Fe}$ edge there is also considerable signal from $\mathrm{Mn}$, while both $\mathrm{Mn}$ and $\mathrm{Fe}$ contribute to the signal at the Co or $\mathrm{Zn}$ edge. To differentiate between the different metals, data therefore have to be collected at all three edges (Griese et al., 2013, 2014). The insets show the anomalous difference density from diffraction data collected at X-ray energies (indicated by arrows) corresponding to the Mn (pink), Fe (orange) and Co (blue) or $\mathrm{Zn}$ (green) absorption edges from crystals of metal-free R2lox soaked with $\mathrm{Mn}^{2+}, \mathrm{Fe}^{2+}$ and $\mathrm{Co}^{2+}$ (top) or $\mathrm{Zn}^{2+}$ (bottom) under aerobic conditions, contoured at 4 e $\AA^{-3}$ (the maps for each crystal 1 are shown; see Table 3 ), with the metal-ion positions indicated for clarity by a purple sphere for site $1(\mathrm{Mn})$ and an orange sphere for site $2(\mathrm{Fe})$. complexes of the divalent ions of first-row transition metals follows the order $\mathrm{Mn}^{2+}<\mathrm{Fe}^{2+}<\mathrm{Co}^{2+}<\mathrm{Ni}^{2+}<\mathrm{Cu}^{2+}>\mathrm{Zn}^{2+}$, essentially regardless of the nature of the coordinating ligand (Irving \& Williams, 1953). Hence, site 1 does not behave according to expectation: the protein scaffold defies the IW series. Dissection of the cofactor-assembly mechanism of R2lox indicated that both thermodynamic and kinetic preferences contribute to the observed metal selectivity, although the precise specificity determinants remain elusive (Griese et al., 2013, 2019; Kutin et al., 2016). Here, we investigated the effect of competition by transition metals higher in the IW series, i.e. Co or $\mathrm{Zn}$, on the metal distribution in the two sites under aerobic conditions using Q-XAD. We describe the quantification method in detail so that it may be used by others to study the metal distribution and assembly mechanisms of complex metallo-cofactors.

\section{Methods}

\subsection{Protein production and crystallization}

Full-length Geobacillus kaustophilus R2lox was purified and crystallized in a metal-free form as described previously (Griese et al., 2013). Crystals of the metal-free protein were soaked in air-saturated mother liquor additionally containing $5 \mathrm{mM}$ each of $\mathrm{MnCl}_{2},\left(\mathrm{NH}_{4}\right)_{2} \mathrm{Fe}\left(\mathrm{SO}_{4}\right)_{2}$ and $\mathrm{CoCl}_{2}$ or $\mathrm{ZnCl}_{2}$ for $24 \mathrm{~h}$ and then briefly washed in cryoprotectant solution [40\%( $w / v)$ PEG 1500, $100 \mathrm{~m} M$ HEPES-Na $\mathrm{pH}$ 7.4] before flash-cooling in liquid nitrogen.

\subsection{Diffraction data collection}

Data were collected at $100 \mathrm{~K}$ with a PILATUS 6M detector on beamline X06SA of the Swiss Light Source (SLS), Villigen, Switzerland, at $50 \mathrm{eV}$ above the theoretical $K$ absorption edge for each metal. Data collection proceeded in the order Fe edge $(7162 \mathrm{eV}), \mathrm{Mn}$ edge $(6589 \mathrm{eV})$ and $\mathrm{Co}(7721 \mathrm{eV})$ or $\mathrm{Zn}$ edge $(9664 \mathrm{eV})$ from the same crystal. For each data set, 360 frames were collected with an oscillation range of $1^{\circ}$, an exposure time of $0.05 \mathrm{~s}$ per frame and attenuation of the incident X-ray beam to $5-15 \%$ of the full intensity, corresponding to a flux of between 3 and $6 \times 10^{10}$ photons s $^{-1}\left(4 \times 10^{11}\right.$ photons s$^{-1}$ at the zinc edge). The absorbed $X$-ray dose for each data set was estimated using RADDOSE-3D (Zeldin et al., 2013; see Table 1). The raw and processed diffraction data have been deposited at Zenodo at https://doi.org/10.5281/zenodo.2657424.

\subsection{Analysis of anomalous diffraction data}

All data sets from one crystal were integrated over the same resolution range with $X D S$ and placed on a common scale with XSCALE (Kabsch, 2010; Table 1). Both scaled and unscaled data sets were analyzed. Anomalous difference maps were calculated with PHENIX (Adams et al., 2010) using the phases from a ligand-free model of R2lox derived from PDB entry 4hr0 (Griese et al., 2013). The intensities of the anomalous difference density peaks in spheres of $1.9 \AA$ radius around the center of the peaks were integrated using MAPMAN (Kleywegt \& Jones, 1996). The relative amounts of each metal in 
Table 1

Data collection and processing.

Values in parentheses are for the outer shell.

\begin{tabular}{|c|c|c|c|c|c|c|}
\hline \multirow{2}{*}{$\begin{array}{l}\text { Crystal } \\
\text { Data set }\end{array}$} & \multicolumn{3}{|l|}{$\mathrm{Mn}+\mathrm{Fe}+\mathrm{Co} 1$} & \multicolumn{3}{|l|}{$\mathrm{Mn}+\mathrm{Fe}+\mathrm{Co} 2$} \\
\hline & Fe edge & Mn edge & Co edge & Fe edge & Mn edge & Co edge \\
\hline Wavelength $(\AA)$ & 1.73 & 1.88 & 1.61 & 1.73 & 1.88 & 1.61 \\
\hline Space group & $I 222$ & $I 222$ & $I 222$ & $I 222$ & $I 222$ & $I 222$ \\
\hline$a, b, c(\AA)$ & $56.00,97.41,128.80$ & $56.00,97.40,128.77$ & $56.01,97.37,128.88$ & $55.92,97.15,128.50$ & $55.92,97.24,128.66$ & $55.89,97.17,128.57$ \\
\hline Completeness (\%) & 99.7 (98.7) & $99.1(96.9)$ & $99.7(99.0)$ & $99.5(97.2)$ & $99.8(98.6)$ & $99.7(98.3)$ \\
\hline$\langle I / \sigma(I)\rangle$ & $12.26(4.57)$ & $12.23(4.75)$ & $12.09(5.09)$ & $11.17(2.55)$ & $10.21(2.19)$ & $10.69(2.57)$ \\
\hline$R_{\text {merge }}(\%)$ & $11.3(29.0)$ & $11.0(26.5)$ & $10.9(25.6)$ & $12.3(56.8)$ & $13.6(64.3)$ & $13.7(60.8)$ \\
\hline$R_{\text {meas }}(\%)$ & $12.3(31.5)$ & $12.0(28.7)$ & $11.9(27.8)$ & $13.3(61.5)$ & $14.7(69.7)$ & $14.8(65.6)$ \\
\hline $\mathrm{CC}_{1 / 2} \ddagger(\%)$ & $99.5(95.3)$ & $99.4(95.8)$ & $99.4(96.4)$ & $99.6(88.0)$ & $99.5(83.4)$ & $99.6(86.9)$ \\
\hline Anomalous signal§ & $0.85(0.71)$ & $0.85(0.72)$ & $1.03(0.80)$ & $0.88(0.75)$ & $0.84(0.72)$ & $1.00(0.73)$ \\
\hline Average dose $\dagger$ (MGy) & 0.94 & 0.62 & 3.38 & 0.70 & 0.62 & 3.38 \\
\hline Resolution range $(\AA)$ & $\begin{array}{l}50.00-3.19 \\
\quad(3.38-3.19)\end{array}$ & $\begin{array}{l}50.00-3.19 \\
\quad(3.38-3.19)\end{array}$ & $\begin{array}{l}50.00-3.19 \\
\quad(3.39-3.19)\end{array}$ & $\begin{array}{l}50.00-3.20 \\
\quad(3.39-3.20)\end{array}$ & $\begin{array}{l}50.00-3.20 \\
\quad(3.39-3.20)\end{array}$ & $\begin{array}{l}50.00-3.20 \\
\quad(3.39-3.20)\end{array}$ \\
\hline Space group & $I 222$ & $I 222$ & $I 222$ & $I 222$ & $I 222$ & $I 222$ \\
\hline$a, b, c(\AA)$ & $56.01,97.66,129.29$ & $56.02,97.64,129.30$ & $56.03,97.56,129.28$ & $55.88,97.62,128.49$ & $55.90,97.58,128.43$ & $55.90,97.56,128.43$ \\
\hline Unique reflections & 11273 (1761) & 11409 (1795) & 11260 (1802) & 11190 (1785) & 11159 (1789) & 11130 (1797) \\
\hline Multiplicity & 7.0 & 6.9 & 7.1 & 6.9 & 6.9 & 7.0 \\
\hline Completeness (\%) & $99.2(95.6)$ & $99.5(97.4)$ & $99.8(98.8)$ & $99.8(99.3)$ & $99.7(98.5)$ & $99.9(99.8)$ \\
\hline$\langle I / \sigma(I)\rangle$ & $12.47(3.59)$ & $11.05(2.63)$ & $20.95(7.20)$ & $16.64(7.25)$ & $14.75(5.33)$ & $25.20(13.67)$ \\
\hline$R_{\text {merge }}(\%)$ & $12.3(47.3)$ & $13.6(58.8)$ & $7.5(24.8)$ & $8.6(20.9)$ & $9.6(28.6)$ & $5.9(11.0)$ \\
\hline$R_{\text {meas }}(\%)$ & $13.2(51.0)$ & $14.7(63.8)$ & $8.1(26.7)$ & $9.3(22.6)$ & $10.4(31.0)$ & $6.4(11.8)$ \\
\hline $\mathrm{CC}_{1 / 2} \ddagger(\%)$ & $99.6(90.9)$ & $99.6(84.5)$ & $99.9(97.4)$ & $99.7(97.9)$ & $99.7(96.0)$ & 99.8 (99.4) \\
\hline Anomalous signal§ & $0.91(0.80)$ & $0.91(0.78)$ & $1.27(0.84)$ & $0.90(0.78)$ & $0.92(0.87)$ & $1.52(0.96)$ \\
\hline
\end{tabular}

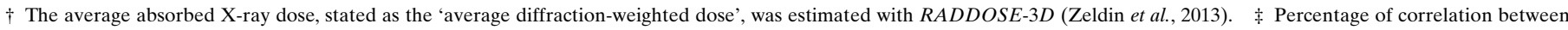

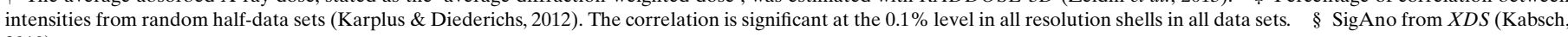
2010).

each site were estimated from the integrated intensities at the $\mathrm{Fe}, \mathrm{Mn}$ and $\mathrm{Co}$ or $\mathrm{Zn}$ edges by taking into account the different contributions of each element to the anomalous signal at each X-ray energy, assuming a total occupancy of each site of 1, as described below.

\section{Theory}

When analyzing the relative amounts of mixtures of metal ions in binding sites by Q-XAD, one needs to take into account that the metal(s) with the lower energy absorption edge(s) will contribute significantly to the anomalous signal at higher energies as well [Fig. 1(b) and Table 2]. In the experiments described here, the metal with the lowest energy absorption edge present in the mixture is Mn. This means that only Mn displays an appreciable anomalous signal at the Mn edge, but at the Fe edge there is also considerable signal from $\mathrm{Mn}$, while both $\mathrm{Mn}$ and $\mathrm{Fe}$ contribute significantly to the signal at the Co or $\mathrm{Zn}$ edge.

The integrated volume of each peak from the anomalous difference density maps at the different wavelengths, $V_{\lambda(M)}$, represents the total occupancy $\alpha_{M}$ of the respective site by all metals contributing to the anomalous signal at that wavelength, multiplied by their contribution to the signal at that wavelength, as defined by the imaginary component of the anomalous dispersion $f^{\prime \prime}$ (see Table 2). To simplify the calculations, we ignore the contributions to the anomalous signal of elements with higher energy absorption edges, as these are within the noise range, similar to the anomalous signal from sulfur at the respective wavelength [see Fig. 1(b) and Table 2]. It should be noted that whether this simplification is justified will depend on the particular mixture of elements analyzed (see below). If judged to be warranted, all contributions can be taken into account using the same formalism, although the equations will be more complicated (see below).

Using this simplification, in the $\mathrm{Mn}+\mathrm{Fe}+\mathrm{Co}$ soaks described here, the integrated peak volumes at the different $\mathrm{X}$-ray energies are then related to the relative occupancies of each site by each metal as follows, where $k$ is a scaling factor:

$$
\begin{gathered}
V_{\lambda(\mathrm{Mn})}=k \times \alpha_{\mathrm{Mn}} \times f_{\mathrm{Mn}, \lambda(\mathrm{Mn})}^{\prime \prime}, \\
V_{\lambda(\mathrm{Fe})}=k\left[\alpha_{\mathrm{Fe}} \times f_{\mathrm{Fe}, \lambda(\mathrm{Fe})}^{\prime \prime}+\alpha_{\mathrm{Mn}} \times f_{\mathrm{Mn}, \lambda(\mathrm{Fe})}^{\prime \prime}\right],
\end{gathered}
$$




$$
V_{\lambda(\mathrm{Co})}=k\left[\alpha_{\mathrm{Fe}} \times f_{\mathrm{Fe}, \lambda(\mathrm{Co})}^{\prime \prime}+\alpha_{\mathrm{Mn}} \times f_{\mathrm{Mn}, \lambda(\mathrm{Co})}^{\prime \prime}+\alpha_{\mathrm{Co}} \times f_{\mathrm{Co}, \lambda(\mathrm{Co})}^{\prime \prime}\right]
$$

The occupancy ratio of Fe:Mn in each site is obtained as follows, using the tabulated values of $f^{\prime \prime}$ at the X-ray energies used given in Table 2,

$$
\begin{aligned}
\frac{V_{\lambda(\mathrm{Fe})}}{V_{\lambda(\mathrm{Mn})}} & =\frac{\alpha_{\mathrm{Fe}} \times f_{\mathrm{Fe}, \lambda(\mathrm{Fe})}^{\prime \prime}+\alpha_{\mathrm{Mn}} \times f_{\mathrm{Mn}, \lambda(\mathrm{Fe})}^{\prime \prime}}{\alpha_{\mathrm{Mn}} \times f_{\mathrm{Mn}, \lambda(\mathrm{Mn})}^{\prime \prime}} \\
& =\frac{\alpha_{\mathrm{Fe}}}{\alpha_{\mathrm{Mn}}} \times \frac{f_{\mathrm{Fe}, \lambda(\mathrm{Fe})}^{\prime \prime}}{f_{\mathrm{Mn}, \lambda(\mathrm{Mn})}^{\prime \prime}}+\frac{f_{\mathrm{Mn}, \lambda(\mathrm{Fe})}^{\prime \prime}}{f_{\mathrm{Mn}, \lambda(\mathrm{Mn})}^{\prime \prime}} \\
\frac{\alpha_{\mathrm{Fe}}}{\alpha_{\mathrm{Mn}}} & =\frac{V_{\lambda(\mathrm{Fe})}}{V_{\lambda(\mathrm{Mn})}} \times \frac{f_{\mathrm{Mn}, \lambda(\mathrm{Mn})}^{\prime \prime}}{f_{\mathrm{Fe}, \lambda(\mathrm{Fe})}^{\prime \prime}}-\frac{f_{\mathrm{Mn}, \lambda(\mathrm{Fe})}^{\prime \prime}}{f_{\mathrm{Fe}, \lambda(\mathrm{Fe})}^{\prime \prime}}
\end{aligned}
$$

and the occupancy ratio of Co:Mn is obtained as

$$
\begin{aligned}
& \frac{V_{\lambda(\mathrm{Co})}}{V_{\lambda(\mathrm{Mn})}}=\frac{\alpha_{\mathrm{Fe}} \times f_{\mathrm{Fe}, \lambda(\mathrm{Co})}^{\prime \prime}+\alpha_{\mathrm{Mn}} \times f_{\mathrm{Mn}, \lambda(\mathrm{Co})}^{\prime \prime}+\alpha_{\mathrm{Co}} \times f_{\mathrm{Co}, \lambda(\mathrm{Co})}^{\prime \prime}}{\alpha_{\mathrm{Mn}} \times f_{\mathrm{Mn}, \lambda(\mathrm{Mn})}^{\prime \prime}} \\
& =\frac{\alpha_{\mathrm{Fe}}}{\alpha_{\mathrm{Mn}}} \times \frac{f_{\mathrm{Fe}, \lambda(\mathrm{Co})}^{\prime \prime}}{f_{\mathrm{Mn}, \lambda(\mathrm{Mn})}^{\prime \prime}}+\frac{f_{\mathrm{Mn}, \lambda(\mathrm{Co})}^{\prime \prime}}{f_{\mathrm{Mn}, \lambda(\mathrm{Mn})}^{\prime \prime}}+\frac{\alpha_{\mathrm{Co}}}{\alpha_{\mathrm{Mn}}} \times \frac{f_{\mathrm{Co}, \lambda(\mathrm{Co})}^{\prime \prime}}{f_{\mathrm{Mn}, \lambda(\mathrm{Mn})}^{\prime \prime}} \\
& =\left[\frac{V_{\lambda(\mathrm{Fe})}}{V_{\lambda(\mathrm{Mn})}} \times \frac{f_{\mathrm{Mn}, \lambda(\mathrm{Mn})}^{\prime \prime}}{f_{\mathrm{Fe}, \lambda(\mathrm{Fe})}^{\prime \prime}}-\frac{f_{\mathrm{Mn}, \lambda(\mathrm{Fe})}^{\prime \prime}}{f_{\mathrm{Fe}, \lambda(\mathrm{Fe})}^{\prime \prime}}\right] \times \frac{f_{\mathrm{Fe}, \lambda(\mathrm{Co})}^{\prime \prime}}{f_{\mathrm{Mn}, \lambda(\mathrm{Mn})}^{\prime \prime}}+\frac{f_{\mathrm{Mn}, \lambda(\mathrm{Co})}^{\prime \prime}}{f_{\mathrm{Mn}, \lambda(\mathrm{Mn})}^{\prime \prime}} \\
& +\frac{\alpha_{\mathrm{Co}}}{\alpha_{\mathrm{Mn}}} \times \frac{f_{\mathrm{Co}, \lambda(\mathrm{Co})}^{\prime \prime}}{f_{\mathrm{Mn}, \lambda(\mathrm{Mn})}^{\prime \prime}} \\
& =\frac{V_{\lambda(\mathrm{Fe})}}{V_{\lambda(\mathrm{Mn})}} \times \frac{f_{\mathrm{Fe}, \lambda(\mathrm{Co})}^{\prime \prime}}{f_{\mathrm{Fe}, \lambda(\mathrm{Fe})}^{\prime \prime}}-\frac{f_{\mathrm{Mn}, \lambda(\mathrm{Fe})}^{\prime \prime} \times f_{\mathrm{Fe}, \lambda(\mathrm{Co})}^{\prime \prime}}{f_{\mathrm{Fe}, \lambda(\mathrm{Fe})}^{\prime \prime} \times f_{\mathrm{Mn}, \lambda(\mathrm{Mn})}^{\prime \prime}}+\frac{f_{\mathrm{Mn}, \lambda(\mathrm{Co})}^{\prime \prime}}{f_{\mathrm{Mn}, \lambda(\mathrm{Mn})}^{\prime \prime}} \\
& +\frac{\alpha_{\mathrm{Co}}}{\alpha_{\mathrm{Mn}}} \times \frac{f_{\mathrm{Co}, \lambda(\mathrm{Co})}^{\prime \prime}}{f_{\mathrm{Mn}, \lambda(\mathrm{Mn})}^{\prime \prime}} \\
& \frac{\alpha_{\mathrm{Co}}}{\alpha_{\mathrm{Mn}}}=\frac{V_{\lambda(\mathrm{Co})}}{V_{\lambda(\mathrm{Mn})}} \times \frac{f_{\mathrm{Mn}, \lambda(\mathrm{Mn})}^{\prime \prime}}{f_{\mathrm{Co}, \lambda(\mathrm{Co})}^{\prime \prime}}-\frac{V_{\lambda(\mathrm{Fe})}}{V_{\lambda(\mathrm{Mn})}} \times \frac{f_{\mathrm{Fe}, \lambda(\mathrm{Co})}^{\prime \prime} \times f_{\mathrm{Mn}, \lambda(\mathrm{Mn})}^{\prime \prime}}{f_{\mathrm{Fe}, \lambda(\mathrm{Fe})}^{\prime \prime} \times f_{\mathrm{Co}, \lambda(\mathrm{Co})}^{\prime \prime}} \\
& +\frac{f_{\mathrm{Mn}, \lambda(\mathrm{Fe})}^{\prime \prime} \times f_{\mathrm{Fe}, \lambda(\mathrm{Co})}^{\prime \prime}}{f_{\mathrm{Fe}, \lambda(\mathrm{Fe})}^{\prime \prime} \times f_{\mathrm{Co}, \lambda(\mathrm{Co})}^{\prime \prime}}-\frac{f_{\mathrm{Mn}, \lambda(\mathrm{Co})}^{\prime \prime}}{f_{\mathrm{Co}, \lambda \mathrm{Co})}^{\prime \prime}} .
\end{aligned}
$$

Assuming a total occupancy of each binding site of 1 , the relative occupancy of $\mathrm{Mn}$ in each site is then obtained as follows:

$$
\begin{gathered}
\alpha_{\text {site }}=1=\alpha_{\mathrm{Mn}}+\alpha_{\mathrm{Fe}}+\alpha_{\mathrm{Co}}=\left(1+\frac{\alpha_{\mathrm{Fe}}}{\alpha_{\mathrm{Mn}}}+\frac{\alpha_{\mathrm{Co}}}{\alpha_{\mathrm{Mn}}}\right) \times \alpha_{\mathrm{Mn}}, \\
\alpha_{\mathrm{Mn}}=1 /\left(1+\frac{\alpha_{\mathrm{Fe}}}{\alpha_{\mathrm{Mn}}}+\frac{\alpha_{\mathrm{Co}}}{\alpha_{\mathrm{Mn}}}\right) .
\end{gathered}
$$

Finally, the occupancies of Fe and Co in each site are obtained by multiplying the occupancy ratios determined in (5) and (7) by the occupancy of Mn from (9). Since only relative amounts are calculated, the actual total occupancy of each site is irrelevant as long as it is high enough to yield a significant anomalous peak, which was the case in all data sets analyzed here.

If no anomalous difference density peak is observed at the Mn edge in a binding site, indicating that the site contains no
Table 2

Tabulated values of the imaginary component $f^{\prime \prime}$ of the anomalous dispersion of $\mathrm{Mn}, \mathrm{Fe}, \mathrm{Co}, \mathrm{Zn}$ and $\mathrm{S}$ at the $\mathrm{X}$-ray energies used in the experiments here, corresponding to the theoretical $K$ absorption edge plus $50 \mathrm{eV}$ (taken from http://skuld.bmsc.washington.edu/scatter/ AS_index.html).

\begin{tabular}{lllll}
\hline & $f^{\prime \prime}(\mathrm{e})$ & & \\
\cline { 2 - 5 } & $\begin{array}{l}6589 \mathrm{eV}(\mathrm{Mn} \\
\text { edge }+50 \mathrm{eV})\end{array}$ & $\begin{array}{l}7162 \mathrm{eV}(\mathrm{Fe} \\
\text { edge }+50 \mathrm{eV})\end{array}$ & $\begin{array}{l}7721 \mathrm{eV}(\mathrm{Co} \\
\text { edge }+50 \mathrm{eV})\end{array}$ & $\begin{array}{l}9664 \mathrm{eV}(\mathrm{Zn} \\
\text { edge }+50 \mathrm{eV})\end{array}$ \\
\hline $\mathrm{Mn}$ & 3.908 & 3.309 & 2.959 & 2.060 \\
$\mathrm{Fe}$ & 0.538 & 3.900 & 3.395 & 2.358 \\
$\mathrm{Co}$ & 0.628 & 0.537 & 3.928 & \\
$\mathrm{Zn}$ & 0.969 & 0.830 & & 3.892 \\
$\mathrm{~S}$ & 0.803 & 0.685 & 0.605 & 0.392 \\
\hline
\end{tabular}

$\mathrm{Mn}$, the relative occupancies of $\mathrm{Fe}$ and $\mathrm{Co}$ are obtained as follows:

$$
\begin{gathered}
\frac{V_{\lambda(\mathrm{Co})}}{V_{\lambda(\mathrm{Fe})}}=\frac{\alpha_{\mathrm{Fe}} \times f_{\mathrm{Fe}, \lambda(\mathrm{Co})}^{\prime \prime}+\alpha_{\mathrm{Co}} \times f_{\mathrm{Co}, \lambda(\mathrm{Co})}^{\prime \prime}}{\alpha_{\mathrm{Fe}} \times f_{\mathrm{Fe}, \lambda(\mathrm{Fe})}^{\prime \prime}} \\
=\frac{f_{\mathrm{Fe}, \lambda(\mathrm{Co})}^{\prime \prime}}{f_{\mathrm{Fe}, \lambda(\mathrm{Fe})}^{\prime \prime}}+\frac{\alpha_{\mathrm{Co}}}{\alpha_{\mathrm{Fe}}} \times \frac{f_{\mathrm{Co}, \lambda(\mathrm{Co})}^{\prime \prime}}{f_{\mathrm{Fe}, \lambda(\mathrm{Fe})}^{\prime \prime}} \\
\frac{\alpha_{\mathrm{Co}}}{\alpha_{\mathrm{Fe}}}=\frac{V_{\lambda(\mathrm{Co})}}{V_{\lambda(\mathrm{Fe})}} \times \frac{f_{\mathrm{Fe}, \lambda(\mathrm{Fe})}^{\prime \prime}}{f_{\mathrm{Co}, \lambda(\mathrm{Co})}^{\prime \prime}}-\frac{f_{\mathrm{Fe}, \lambda(\mathrm{Co})}^{\prime \prime}}{f_{\mathrm{Co}, \lambda(\mathrm{Co})}^{\prime \prime}} \\
\alpha_{\mathrm{Fe}}=1 /\left(1+\frac{\alpha_{\mathrm{Co}}}{\alpha_{\mathrm{Fe}}}\right), \\
\alpha_{\mathrm{Co}}=1-\alpha_{\mathrm{Fe}} .
\end{gathered}
$$

Equations (10)-(13) also apply if only two different metal ions were used in the experiment.

Equally, replace $\alpha_{\mathrm{Co}}$ with $\alpha_{\mathrm{Zn}}$ and $\lambda(\mathrm{Co})$ with $\lambda(\mathrm{Zn})$ in the above equations to obtain the relative occupancies of $\mathrm{Mn}, \mathrm{Fe}$ and $\mathrm{Zn}$ in the $\mathrm{Mn}+\mathrm{Fe}+\mathrm{Zn}$ soaks. However, since the anomalous signal of $\mathrm{Zn}$ at the $\mathrm{Mn}$ and $\mathrm{Fe}$ edges is relatively high (see Table 2), ignoring its contribution to the peak volumes at these wavelengths may introduce too large an error to the quantification. In this case, the following equations should be used:

$$
\begin{gathered}
V_{\lambda(\mathrm{Mn})}=k\left[\alpha_{\mathrm{Mn}} \times f_{\mathrm{Mn}, \lambda(\mathrm{Mn})}^{\prime \prime}+\alpha_{\mathrm{Zn}} \times f_{\mathrm{Zn}, \lambda(\mathrm{Mn})}^{\prime \prime}\right] \\
V_{\lambda(\mathrm{Fe})}=k\left[\alpha_{\mathrm{Fe}} \times f_{\mathrm{Fe}, \lambda(\mathrm{Fe})}^{\prime \prime}+\alpha_{\mathrm{Mn}} \times f_{\mathrm{Mn}, \lambda(\mathrm{Fe})}^{\prime \prime}+\alpha_{\mathrm{Zn}} \times f_{\mathrm{Zn}, \lambda(\mathrm{Fe})}^{\prime \prime}\right],
\end{gathered}
$$

$$
V_{\lambda(\mathrm{Zn})}=k\left[\alpha_{\mathrm{Fe}} \times f_{\mathrm{Fe}, \lambda(\mathrm{Zn})}^{\prime \prime}+\alpha_{\mathrm{Mn}} \times f_{\mathrm{Mn}, \lambda(\mathrm{Zn})}^{\prime \prime}+\alpha_{\mathrm{Zn}} \times f_{\mathrm{Zn}, \lambda(\mathrm{Zn})}^{\prime \prime}\right] .
$$

These equations can be solved by elimination, but as the results in this case are the same as those obtained with the simplified equations within error (see below), we will not provide the solutions here.

\section{Results}

Anomalous diffraction data were collected from four $(\mathrm{Mn}+$ $\mathrm{Fe}+\mathrm{Co})$ or three $(\mathrm{Mn}+\mathrm{Fe}+\mathrm{Zn})$ crystals for each soak. For 
Table 3

Relative amounts of $\mathrm{Mn}, \mathrm{Fe}$ and $\mathrm{Co}$ or $\mathrm{Zn}$ in the two metal sites obtained when soaking crystals of metal-free R2lox with an excess of $\mathrm{Mn}^{2+}, \mathrm{Fe}^{2+}$ and $\mathrm{Co}^{2+}$ or $\mathrm{Zn}^{2+}$ in equal concentrations (5 $\mathrm{m} M$ each) under aerobic conditions.

Relative metal amounts are derived from the integrated intensity of the anomalous difference density peaks at the $\mathrm{Mn}, \mathrm{Fe}$ and $\mathrm{Co}$ or $\mathrm{Zn}$ absorption edges. The quantification results for scaled data sets are shown.

$\mathrm{Mn}+\mathrm{Fe}+$ Co soak.

\begin{tabular}{llllllll}
\hline & \multicolumn{1}{l}{ Site 1} & & & & Site 2 & & \\
\cline { 2 - 3 } Crystal & $\mathrm{Mn}$ & $\mathrm{Fe}$ & $\mathrm{Co}$ & & $\mathrm{Mn}$ & $\mathrm{Fe}$ & Co \\
\hline 1 & 0.61 & 0.07 & 0.31 & & 0.00 & 0.64 & 0.36 \\
2 & 0.57 & 0.12 & 0.31 & & 0.00 & 0.66 & 0.34
\end{tabular}

$\mathrm{Mn}+\mathrm{Fe}+\mathrm{Zn}$ soak

\begin{tabular}{llllllll}
\hline & \multicolumn{2}{l}{ Site 1} & & & \multicolumn{2}{l}{ Site 2} \\
Crystal & Mn & Fe & Zn & & Mn & Fe & Zn \\
\hline 1 & 0.44 & 0.02 & 0.54 & & 0.16 & 0.28 & 0.56 \\
3 & 0.27 & 0.14 & 0.59 & & 0.10 & 0.33 & 0.57 \\
\hline
\end{tabular}

two crystals in each $\mathrm{Mn}+\mathrm{Fe}+\mathrm{Co} / \mathrm{Zn}$ soak (metal salts at $5 \mathrm{~m} M$ each), sets of anomalous data sets of high enough quality for Q-XAD were obtained (Table 1). The quantification results for scaled and unscaled data sets matched within $0-2 \%$ ( $5 \%$ for the relative occupancy of $\mathrm{Mn}$ and Fe in site 1 of $\mathrm{Mn}+\mathrm{Fe}+\mathrm{Zn}$ crystal 1). The results for the two crystals from the same soak were the same within $0-9 \%$ (Table 3), indicating that the quantification is robust.

$\mathrm{Co}$ and $\mathrm{Zn}$ were observed in both metal-binding sites of R2lox, but despite being stronger binders according to the IW series they did not outcompete the other metal ions completely [Fig. 1(b), Table 3]. As expected based on the IW series, $\mathrm{Zn}$ bound better than $\mathrm{Co}$, with both sites containing $\sim 30 \%$ Co or $\sim 60 \% \mathrm{Zn}$ in the respective soak. However, the remaining fraction of metal in addition to Co or $\mathrm{Zn}$ was mainly $\mathrm{Mn}$ in site 1 and $\mathrm{Fe}$ in site 2 in both competition experiments. Hence, the sites retain their selectivity even in the presence of competitors. This result underscores that metal selectivity in R2lox is structurally encoded (Griese et al., 2013). In cells, the $\mathrm{Mn}^{2+}$ and $\mathrm{Fe}^{2+}$ concentrations are generally kept in a similar low-micromolar range, while the $\mathrm{Co}^{2+}$ and $\mathrm{Zn}^{2+}$ concentrations are several orders of magnitude lower in order to prevent metalloenzymes from being metallated by the wrong metals (Dudev \& Lim, 2014). In vivo, R2lox is consequently unlikely to ever be poisoned by $\mathrm{Co}$ or $\mathrm{Zn}$, as in this experiment. It is therefore all the more remarkable that the enzyme is able to select $\mathrm{Mn}$ in site 1 and Fe in site 2 when faced with competition from these much stronger binders.

As pointed out above, $\mathrm{Fe}, \mathrm{Co}$ and $\mathrm{Zn}$ contribute to the anomalous signal at the Mn edge [Fig. 1(b) and Table 2].

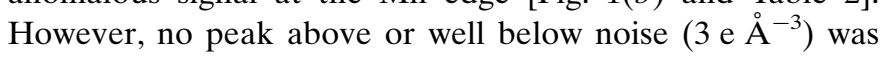
observed in metal site 2 of R2lox in the Mn-edge anomalous maps of the $\mathrm{Mn}+\mathrm{Fe}+\mathrm{Co}$ soaks, although the Fe-edge and $\mathrm{Co}$-edge data show that $\mathrm{Fe}$ and $\mathrm{Co}$ are present in site 2. These elements therefore do not contribute significantly to the anomalous signal at the Mn edge and, by extension, we can conclude that Co will not contribute significantly to the anomalous signal at the Fe edge (see Table 2). The simplification of our calculations (see Section 3) therefore appears justified in the case of the $\mathrm{Mn}+\mathrm{Fe}+\mathrm{Co}$ soaks, as it will not introduce additional error into the quantification.

The anomalous signal from $\mathrm{Zn}$ at the $\mathrm{Mn}$ and Fe edges is significantly higher than that from Co [Fig. 1(b) and Table 2]. In the $\mathrm{Mn}+\mathrm{Fe}+\mathrm{Zn}$ soaks there are peaks in site 2 at the $\mathrm{Mn}$ edge at or slightly above the noise level (3 e $\AA^{-3}$; see Table 3 ). Given the simplified equations used in our calculations, which assume that only Mn contributes to the signal at the Mn edge, we cannot exclude that $\mathrm{Zn}$ contributed to these signals in site 2. We therefore also calculated the relative occupancies of $\mathrm{Mn}$, $\mathrm{Fe}$ and $\mathrm{Zn}$ in the metal-binding sites by taking the contribution of $\mathrm{Zn}$ to the signal at the $\mathrm{Mn}$ and Fe edges into account (while still ignoring the contribution of Fe to the signal at the $\mathrm{Mn}$ edge), as described in Section 3. The results were within $10 \%$ of those obtained with the full simplification, i.e. within the error range of the method. We therefore conclude that even in this case the simplification can be used.

\section{Discussion}

While methods have been developed to quantify the relative amounts of different transition-metal ions in small-molecule binding sites by anomalous dispersion (Brozek et al., 2013), these methods rely on sub-ångström resolution because they require extremely accurate occupancy determination, and are consequently not generally applicable in macromolecular crystallography. Here, we describe a method which can be applied to metalloprotein crystals of average quality.

Anomalous data collected at multiple wavelengths have previously been used to unambiguously and site-specifically identify metal ions in crystals of the endoproteinase furin (Than et al., 2005). However, our method is a substantial improvement over the method described by Than et al. (2005) because it uses the anomalous difference density maps directly without further manipulation that may introduce errors. Than et al. (2005) calculated element-specific 'difference anomalous difference' maps, which would, if we take the example of a Mn versus Fe competition experiment, mean that the contribution of $\mathrm{Mn}$ to the anomalous signal at the Fe edge is subtracted [see Fig. 1(b)]. In practice this is accomplished by collecting data sets at (or slightly above) both absorption edges, calculating anomalous maps for both and then subtracting the $\mathrm{Mn}$ anomalous map from the Fe anomalous map. We have tested this method and found it to introduce large errors, as the peaks in the resulting difference anomalous difference maps were generally not well shaped (i.e. round). It would therefore be even less reliable if it was extended beyond two different metals. Our Q-XAD method does not suffer from this limitation, as it does not introduce additional errors through unnecessary map manipulations.

Anomalous data have also previously been used to obtain a rough idea of the relative occupancies of different metal ions (Dassama et al., 2012, 2013; Cuesta-Seijo et al., 2006; Weiss et al., 2002), but no attempts to calculate the relative amounts 
were made in these studies. Moreover, either no quantitative information was extracted from the data at all, or peak heights were determined, rather than the integrated peak volumes used here, which afford a far more accurate quantification. To our knowledge, MAPMAN (Kleywegt \& Jones, 1996) is the only software that can integrate peak volumes.

Q-XAD is the only metal-quantification method that provides location-specific information. Our results show that Q-XAD is reliable (Griese et al., 2013, 2019; Kutin et al., 2016). We have previously shown that the quantification results agree with those obtained by other methods such as EPR and Mössbauer spectroscopy as well as TXRF (Kutin et al., 2016). Given that the crystals are of high enough quality and the data are collected carefully, the error of the method is in the range of $10 \%$.

In the equations provided here, we make the assumption that only elements with lower energy absorption edges contribute significantly to the anomalous signal at a given $\mathrm{X}$-ray energy, thus ignoring the contribution from elements with higher energy edges. Our results show that while this simplification is not strictly correct, the error that it introduces is within the inherent error of the method. These simple equations can thus be applied to anomalous data from protein crystals containing mixtures of other transition-metal ions.

The R2lox crystals used in this study diffracted to a maximum resolution of $\sim 1.8 \AA$ and displayed relatively high $B$ factors (Griese et al., 2013, 2015). They are therefore not of above-average quality, indicating that Q-XAD can be applied to a wide range of metalloproteins. Q-XAD can be used to study the cofactor-assembly mechanisms and metal specificity of metalloproteins in vitro. Using the method described here, complex competition experiments are possible.

\section{Detailed description and advice on the use of the Q-XAD method}

\subsection{Crystallization}

To obtain an error estimate of the quantification, at least two good sets of data sets are needed per condition tested, and ideally more, which generally requires data collection from a larger number of crystals. The method is therefore most suitable for metalloproteins which crystallize with good reproducibility. The crystals should diffract to at least $2.5 \AA$ resolution (at short wavelengths). The crystal system should be well characterized before embarking on Q-XAD experiments.

\subsection{Data collection}

Q-XAD requires a significant amount of beamtime. Data have to be collected at all X-ray absorption edges of interest from the same crystal. As wavelength changes take much longer than changing sample, and have the potential to disrupt beamline operations, these changes must be minimized, which means that the data sets have to be collected wavelength by wavelength rather than crystal by crystal. A beamline with a reliable automatic sample changer is therefore desirable.
It is recommended that a fluorescence scan be performed on one crystal to determine the exact absorption edges of the metal ions in the crystal. However, as these may shift slightly from one crystal to another, especially if different conditions are used (e.g. a reduced versus an oxidized state of a redoxactive metal cluster), we recommend choosing an X-ray energy slightly above the absorption edge in order to be certain that the energy is never below the edge. In our experiments, we used the theoretical edge plus $50 \mathrm{eV}$ (Griese et al., 2013, 2019; Kutin et al., 2016).

While R2lox crystals are remarkably resistant to radiation damage, and in initial experiments we found that the order of data collection at the different wavelengths did not influence the quantification results, we recommend that data be collected in different orders from a few crystals in initial tests (e.g. Fe edge followed by Mn edge as well as the reverse order) to ensure that the quantification results are not skewed by radiation damage.

Since anomalous differences have to be determined with the highest possible accuracy, data sets should be collected with high multiplicity $\left(360^{\circ}\right.$ rotation, corresponding to a multiplicity of $\sim 7$, in our experiments; see Table 1). At the same time, each crystal has to survive several rounds of data collection (three in the case described here) without appreciable radiation damage that would drown out the small anomalous differences, meaning that the X-ray dose used has to be minimized and should ideally be in the range of the dose limit for sulfur SAD phasing, i.e. around 3-5 MGy (Storm et al., 2017). Data sets therefore need to be collected using a highly attenuated beam and short exposure times. Resolution is not important as long as the data are of high quality. A resolution of around $3 \AA$ is sufficient. Note that at long wavelengths the beamline geometry can limit the maximum resolution to this range owing to the minimum detector distance. (MAPMAN also cannot process map files above a certain size, so high-resolution maps cannot be used.) Fine $\varphi$-slicing is generally beneficial for data quality, and especially for anomalous signal (Mueller et al., 2012). However, given that several data sets have to be collected from each crystal, to minimize the dose and at the same time obtain images with strong enough diffraction to be integrated accurately, it can be better not to collect data with oscillation ranges that are too small. In our experiments, we generally used oscillation ranges of $0.5^{\circ}$ or $1^{\circ}$.

\subsection{Data processing}

As a large number of data sets have to be processed, it is recommended that the autoprocessing pipeline available at the beamline be taken advantage of. However, all data sets from one crystal have to be integrated over the same resolution range. Some pipelines may allow some processing parameters to be enforced, but if not, providing a specific resolution cutoff later is still faster than processing the data from scratch.

Only the highest quality data sets should be taken forward for quantification. The aim is not to phase a structure, which 


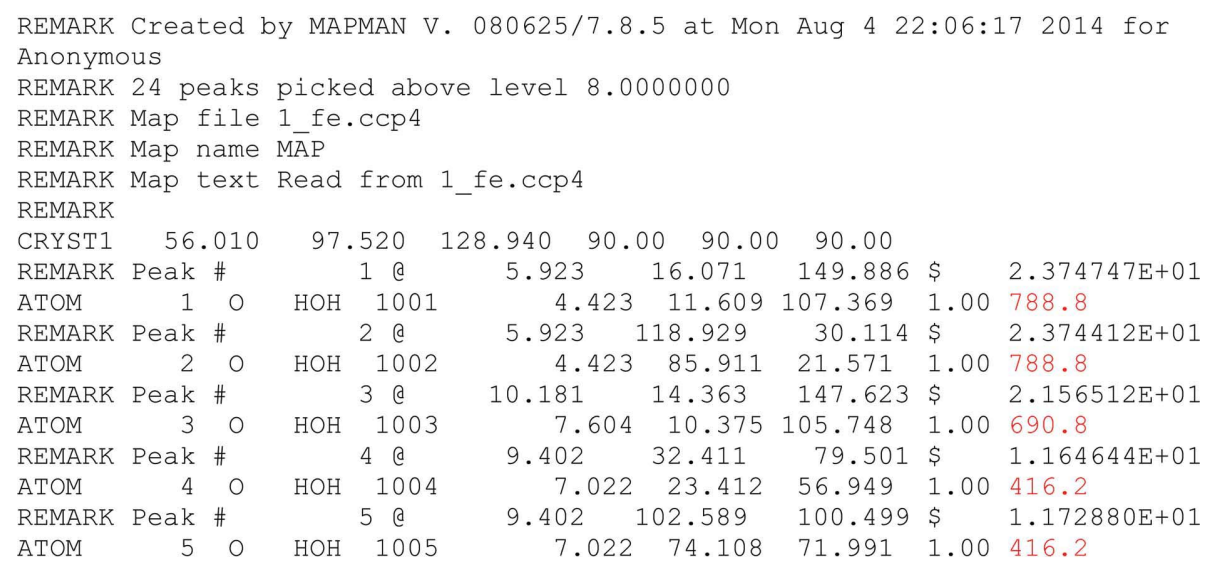

Figure 2

The name2.pdb file.

can be possible with marginal anomalous data; the aim is to obtain the most accurate anomalous differences in order to quantify the relative amounts of different metal ions in a binding site. In our experience, this requires very conservative data-quality standards, i.e. a low overall $R_{\text {merge }} / R_{\text {meas, }}$ a high signal-to-noise ratio ( $\geq 1.5$ in the highest resolution shell), high completeness (especially at low resolution), significant $\mathrm{CC}_{1 / 2}$ throughout and good anomalous correlation. It is, however, unlikely that you will see a significant anomalous correlation in the high-resolution shells.

All data sets from one crystal should be put on a common scale. The quantification should then be performed for both scaled and unscaled data. If the results for scaled versus unscaled data from one crystal differ by more than $10 \%$ then the data are not good enough.

\subsection{Anomalous maps}

Use a ligand-free model of your protein to calculate anomalous maps for all data sets and inspect them visually. The maps must be in . ccp 4 format. (Tip: choose short names for your maps, as you will have to type them out in MAPMAN.) They should have well shaped round peaks far above the noise level at the expected positions of the metal ions. At longer wavelengths you should also expect to see small peaks for well ordered sulfurs in the structure. Determine the $\sigma$ level at which the peaks for the metal ions disappear. In $M A P M A N$, you will only pick peaks above this level in order to obtain the shortest possible list of peaks, ideally only those corresponding to the metal ions. Also determine the radius of each metal-ion peak. Make a note of the radius that covers the entire metal-ion peak but does not overlap with any other anomalous peaks.

\subsection{Quantification}

MAPMAN (Kleywegt \& Jones, 1996) and a manual for it can be found at the Uppsala Software Factory (http:// xray.bmc.uu.se/usf/). It is a command-line program which runs on Linux platforms. (The executables do not run on newer versions of Mac OS, but could probably be compiled.) Note that the tab stop autocomplete command does not work in $M A P M A N$, but there are command shortcuts which we do not specify here.

6.5.1. Step-by-step instructions. Navigate into the folder that contains the maps. Type the following commands:

\section{$>$ mapman}

>read map name. ccp 4 ccp 4

This tells MAPMAN to read in your map file and give it the name 'map', and tells it that the map is in . c cp 4 format.

>normalise map

This gives the map an average value of zero and a standard deviation of one by first subtracting the average and then dividing by the old standard deviation. This should be performed when comparing different maps, but in practice it does not affect the results significantly.

$>$ pick level 8

This tells $M A P M A N$ to pick all peaks in the map above $\sigma$ level 8. Choose the appropriate $\sigma$ level as determined during map inspection.

\section{$>$ pick peaks map name1.pdb pdb}

This tells $M A P M A N$ to write out the peaks that it picked in 'map' to a .pdb file.

>peek sphere map name1.pdb name2.pdb int 1.9

This tells MAPMAN to integrate the map around the peaks it picked in spheres of $1.9 \AA$ radius. Choose the appropriate radius as determined during map inspection.

The name2 pdb file will be as shown in Fig. 2.

$M A P M A N$ puts water molecules at all of the peaks it finds above the specified $\sigma$ level. The ATOM line contains the coordinates $(x, y, z)$, occupancy $(=1)$ and the integrated peak volume in the $B$-factor column (marked in red in Fig. 2).

Open the same . pdb file in a molecular-graphics program along with your protein model and the map, and go through the water molecules to determine which one corresponds to which peak.

Use the integrated peak volumes in the equations described in Section 3 to determine the relative occupancy of each metal in each site. 


\subsection{Internal reference}

In our R2lox model system there is a surface histidine residue which binds a metal ion in crystal-soaking experiments in which high concentrations of metal ions are used. This metal site turned out to be a very useful internal reference, as the ratio of the integrated volumes of this peak and the metal cofactor site peaks at each wavelength, which is indicative of their relative occupancy, should always be approximately the same under the same conditions. Consequently, if the ratio differs significantly from the average, this is an indication that at least one of the data sets in the set is not of sufficient quality. (In $\mathrm{Mn}+\mathrm{Fe}$ soaks this site is occupied by $\mathrm{Fe}$ under anoxic conditions, as Fe has higher affinity according to the IW series, but by $\mathrm{Mn}$ under aerobic conditions, as $\mathrm{Fe}^{2+}$ becomes oxidized to $\mathrm{Fe}^{3+}$ and precipitates. In the three-metal soaks described here this site was occupied by Co or $\mathrm{Zn}$, respectively: the strongest binder according to the IW series.)

\section{Acknowledgements}

We thank Matthew D. Bennett and the staff of beamline X06SA at SLS for assistance with X-ray data collection and Alwyn Jones for advice on the use of MAPMAN.

\section{Funding information}

The following funding is acknowledged: Vetenskapsrådet (grant No. 2016-03770 to Julia J. Griese; grant No. 2017-04018 to Martin Högbom); European Research Council (grant No. HIGH-GEAR 724394 to Martin Högbom); Knut och Alice Wallenbergs Stiftelse (grant Nos. 2012.0233 and 2017.0275 to Martin Högbom); European Community Seventh Framework Programme (FP7/2007-2013) for BioStruct-X (grant No. 283570 to Martin Högbom).

\section{References}

Adams, P. D., Afonine, P. V., Bunkóczi, G., Chen, V. B., Davis, I. W., Echols, N., Headd, J. J., Hung, L.-W., Kapral, G. J., GrosseKunstleve, R. W., McCoy, A. J., Moriarty, N. W., Oeffner, R., Read,
R. J., Richardson, D. C., Richardson, J. S., Terwilliger, T. C. \& Zwart, P. H. (2010). Acta Cryst. D66, 213-221.

Andersson, C. S. \& Högbom, M. (2009). Proc. Natl Acad. Sci. USA, 106, 5633-5638.

Andreini, C., Bertini, I., Cavallaro, G., Holliday, G. L. \& Thornton, J. M. (2008). J. Biol. Inorg. Chem. 13, 1205-1218.

Bowman, S. E. J., Bridwell-Rabb, J. \& Drennan, C. L. (2016). Acc. Chem. Res. 49, 695-702.

Brozek, C. K., Cozzolino, A. F., Teat, S. J., Chen, Y.-S. \& Dincă, M. (2013). Chem. Mater. 25, 2998-3002.

Cuesta-Seijo, J. A., Weiss, M. S. \& Sheldrick, G. M. (2006). Acta Cryst. D62, 417-424.

Dassama, L. M., Boal, A. K., Krebs, C., Rosenzweig, A. C. \& Bollinger, J. M. Jr (2012). J. Am. Chem. Soc. 134, 2520-2523.

Dassama, L. M., Krebs, C., Bollinger, J. M. Jr, Rosenzweig, A. C. \& Boal, A. K. (2013). Biochemistry, 52, 6424-6436.

Dudev, T. \& Lim, C. (2014). Chem. Rev. 114, 538-556.

Griese, J. J., Branca, R. M. M., Srinivas, V. \& Högbom, M. (2018). J. Biol. Inorg. Chem. 23, 879-886.

Griese, J. J., Kositzki, R., Haumann, M. \& Högbom, M. (2019). J. Biol. Inorg. Chem. 24, 211-221.

Griese, J. J., Kositzki, R., Schrapers, P., Branca, R. M. M., Nordström, A., Lehtiö, J., Haumann, M. \& Högbom, M. (2015). J. Biol. Chem. 290, 25254-25272.

Griese, J. J., Roos, K., Cox, N., Shafaat, H. S., Branca, R. M. M., Lehtiö, J., Gräslund, A., Lubitz, W., Siegbahn, P. E. M. \& Högbom, M. (2013). Proc. Natl Acad. Sci. USA, 110, 17189-17194.

Griese, J. J., Srinivas, V. \& Högbom, M. (2014). J. Biol. Inorg. Chem. 19, 759-774.

Irving, H. \& Williams, R. J. P. (1953). J. Chem. Soc., pp. 3192-3210.

Kabsch, W. (2010). Acta Cryst. D66, 125-132.

Karplus, P. A. \& Diederichs, K. (2012). Science, 336, 1030-1033.

Kleywegt, G. J. \& Jones, T. A. (1996). Acta Cryst. D52, 826-828.

Kutin, Y., Srinivas, V., Fritz, M., Kositzki, R., Shafaat, H. S., Birrell, J., Bill, E., Haumann, M., Lubitz, W., Högbom, M., Griese, J. J. \& Cox, N. (2016). J. Inorg. Biochem. 162, 164-177.

Mueller, M., Wang, M. \& Schulze-Briese, C. (2012). Acta Cryst. D68, $42-56$.

Storm, S. L. S., Dall'Antonia, F., Bourenkov, G. \& Schneider, T. R. (2017). J. Synchrotron Rad. 24, 19-28.

Than, M. E., Henrich, S., Bourenkov, G. P., Bartunik, H. D., Huber, R. \& Bode, W. (2005). Acta Cryst. D61, 505-512.

Weiss, M. S., Panjikar, S., Nowak, E. \& Tucker, P. A. (2002). Acta Cryst. D58, 1407-1412.

Zeldin, O. B., Gerstel, M. \& Garman, E. F. (2013). J. Appl. Cryst. 46, 1225-1230. 